\title{
Experimental study for Infrared Temperature Measurement System
}

\author{
Zipeng $\mathrm{GUO}^{1,}$, , Jinxia $\mathrm{CHU}^{2, \mathrm{~b}_{\text {, }}}$ \\ ${ }^{1}$ Automobile Institute, Hubei Polytechnic Institute, Xiaogan 432000, China; \\ 2 School of Fine Art \& Design, Hubei Engineering University, Xiaogan 432000, China \\ a 409461117 @qq.com, b346917126@qq.com \\ ${ }^{*}$ Corresponding author
}

Keywords: infrared temperature measurement system, experimental study, measurement distance.

\begin{abstract}
Based on C51 microcontroller and infrared temperature sensor. The experimental study is executed for the character of designed system, and the results show as follows: for the range of $2.5-15 \mathrm{~cm}$, the error of measurement error is very small, less than $1{ }^{\circ} \mathrm{C}$; but in between $20-27 \mathrm{~cm}$, the error increased gradually. Overall the infrared thermometer ace achieve stable measurement with high precision and can be widely used in families, hospitals, schools, etc., and has good popularization and application prospect.
\end{abstract}

\section{Introduction}

With the rapid development and application of temperature measurement technology, in the face of increasing demand, temperature measurement has wide application prospect in various fields of the temperature measurement technology used in medical work, industrial equipment fault detection, military reconnaissance, civilian daily life etc.[1,4]. The traditional mercury thermometer due to long time measuring and reading trouble and the interference of the body temperature and other shortcomings, has been unable to meet the measurement needs of the people, and the electronic thermometer is due to contact with the patient and bring the risk of infection[5,8].

Based on C51 microcontroller, TN infrared temperature sensor, voice broadcast module and display module design and implementation of infrared temperature measurement system. In this paper, the circuit diagram of hardware design and the flow chart of software algorithm are described.

\section{The Overall Diagram for the Designed System}

The overall diagram for Infrared temperature measurement system is shown in Figure 1, which is composed of MCU, infrared temperature sensor, power supply module, extended keys, the liquid crystal display module and voice broadcast module. the MCU is the microcontroller STC12C5A60S2 using LQFP-44 package with high performance and high performance, the enhanced 8051 core, 36 common IO port, 8 Road the 12 bit ADC module, and other standard peripherals, and can fully meet the system requirements. The infrared temperature sensor directly adopts a commercially available sensor module with digital output, this module is used for collecting and measuring temperature data, and sent the data to the microcontroller port. The extended keys adopts the standard $4 \times 4$ keyboard, used for human-computer interaction input keys. The liquid crystal display module is the NOKIA 5110 screen to replace the conventional LCD1602, it has a cost-effective, simple interface (only four IO lines can be driven), high-speed (display speed is several times the general LCD12864 or LCD1602), low voltage and low power consumption. this module is used for data display and output of human-computer interaction display. Voice broadcast module is a commercially available voice module, only 3 IO port to achieve voice broadcast control. 


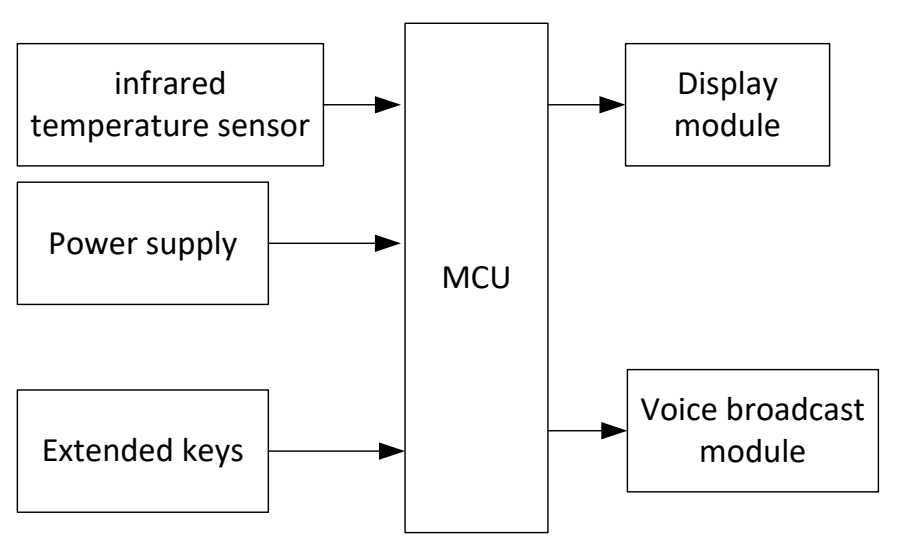

Fig.1 the overall diagram for the designed system

The infrared sensor continuously collects the human body temperature data, and communicates with the MCU controller. When there is an external key press, the controller reads the sensor temperature data, and carries on the digital smoothing filter, then displays the current temperature data, and carries on the real-time speech broadcast.

\section{The Flow Chart for the Designed Software}

The work flow of the system is shown in Figure 2, when the infrared thermometer is connected to the power supply, the STC89C51 microcontroller starts to run the program. The program first STC89C51 microcontroller initialization, and then wait for the timing interrupt, read the temperature sensing data of the infrared temperature measurement module, after the data smoothing filter, the display module to send data. Finally, to determine whether there is an external interrupt (i.e. whether to press the button for voice broadcast), if there is no external interrupt, then continue to determine if there is an external interrupt; otherwise, sends the data to the voice module through the serial communication, the voice module will receive the data through the speaker.

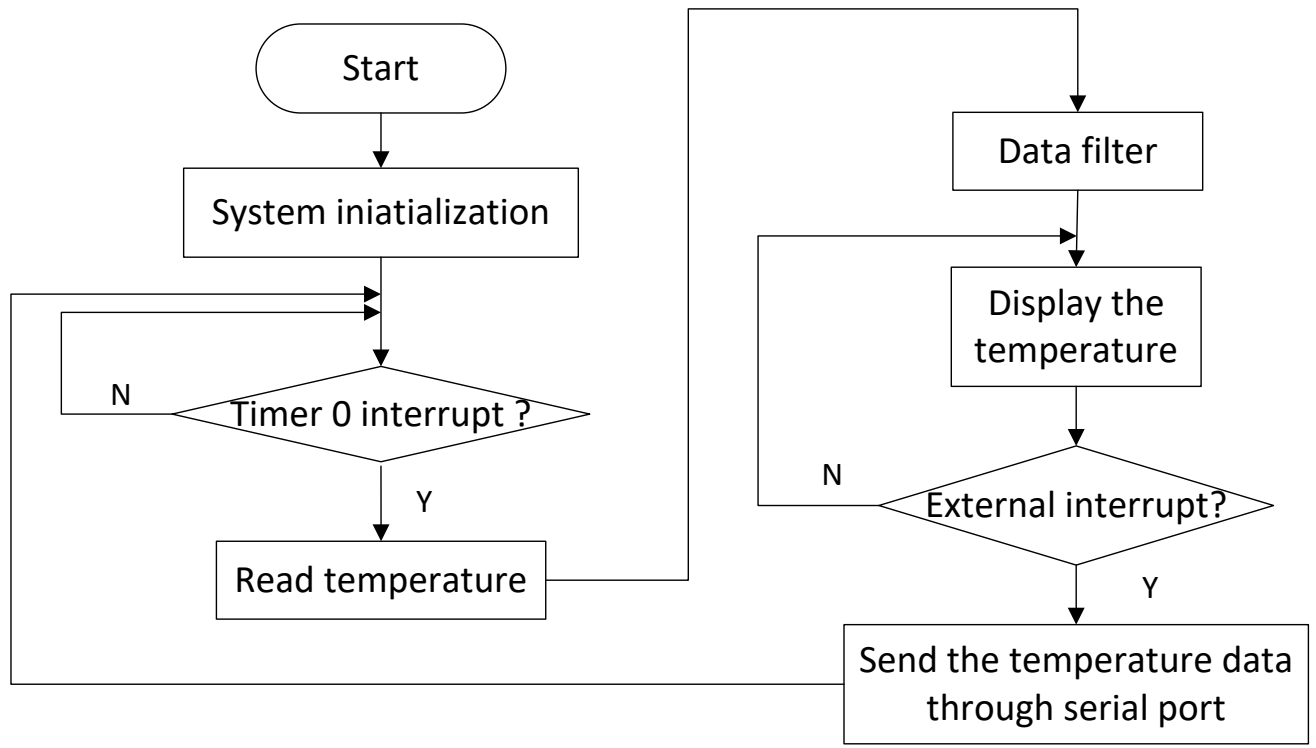

Fig. 2 the flow chart for the designed system software

\section{Experiment and Data Analyzation}

Influence of Distance on Measurement Results. The experimental results are shown in Table 1, for the range of $2.5-15 \mathrm{~cm}$, the error of measurement error is very small, less than $1{ }^{\circ} \mathrm{C}$; but in between $20-27 \mathrm{~cm}$, the error increased gradually; while in more than $30 \mathrm{~cm}$, the test instrument can not measure the temperature. These characteristics are related to the characteristics of the infrared temperature sensor, the basic test distance of the sensor is $0-15 \mathrm{~cm}$, which is basically consistent with the experimental results 
Tab. 1 experimental data for different measure distance

\begin{tabular}{ccc}
\hline Measurement distance/cm & $\begin{array}{l}\text { Measured } \\
\text { value } /{ }^{\circ} \mathrm{C}\end{array}$ & Actual value $/{ }^{\circ} \mathrm{C}$ \\
\hline 2.5 & 50.8 & 50 \\
5 & 49.3 & 50 \\
7.5 & 45.2 & 45 \\
10 & 42.1 & 40 \\
15 & 39.1 & 40.2 \\
20 & 38.8 & 40.1 \\
25 & 36.4 & 40.2 \\
26 & 35.6 & 40.1 \\
27 & 34.4 & 40.1 \\
30 & $/$ & 40.1 \\
\hline
\end{tabular}

Analysis of Test Data at Different Temperatures.The infrared thermometer is used to measure the temperature of different objects, with test range of $20-65^{\circ} \mathrm{C}$, and measurement distance in the range of $15 \mathrm{~cm}$. The test data are shown in Table 2, the results confirmed that the test results are all normal, the infrared thermometer ace achieve stable measurement with high precision.

Tab. 2 experimental data for different temperature

\begin{tabular}{ccc}
\hline number & Measured value $/{ }^{\circ} \mathrm{C}$ & Actual value $/{ }^{\circ} \mathrm{C}$ \\
\hline 1 & 50 & 50 \\
2 & 49.8 & 50 \\
3 & 45.2 & 45 \\
4 & 42.1 & 42.0 \\
5 & 39.8 & 40.0 \\
6 & 38.8 & 39.0 \\
7 & 36.9 & 37.1 \\
8 & 36.3 & 36.1 \\
9 & 34.4 & 34.3 \\
10 & 31.5 & 31.4 \\
\hline
\end{tabular}

Analysis of Temperature Test Data for Human Body. The temperature measurement of 3 human bodies was carried out by using traditional mercury thermometer and infrared thermometer. Among them, the mercury thermometer to test the armpit temperature; infrared thermometer to test the forehead temperature, distance control at around 5CM, and the subjects forehead without sweat and debris. From the measurement results shown in Table 3, the results show that the mercury thermometer measured by the same body temperature and infrared thermometer measured temperature error of around $\pm 0.2^{\circ} \mathrm{C}$.

Tab. 3 experimental data for different human body

\begin{tabular}{cccc}
\hline Num & $\begin{array}{c}\text { Measured value for } \\
\text { design system } /{ }^{\circ} \mathrm{C}\end{array}$ & $\begin{array}{c}\text { Actual } \\
\text { value } /{ }^{\circ} \mathrm{C}\end{array}$ & $\begin{array}{c}\text { measured value for } \\
\text { mercury }\end{array}$ \\
\hline 1 & 36.5 & 36.4 & 36.4 \\
2 & 36.5 & 36.4 & 36.5 \\
3 & 37.5 & 37.3 & 37.5 \\
4 & 37.5 & 37.4 & 37.4 \\
5 & 36.7 & 36.6 & 36.7 \\
6 & 36.7 & 36.6 & 36.6 \\
\hline
\end{tabular}




\section{Conclusions}

Infrared temperature measurement has the advantages of no need to contact the measured object, convenient measurement, high measuring speed and high precision. So, the design and implementation of infrared temperature measurement system is achieved and the experimental study is executed, and the results show as follows: for the range of $2.5-15 \mathrm{~cm}$, the error of measurement error is very small, less than $1{ }^{\circ} \mathrm{C}$; but in between $20-27 \mathrm{~cm}$, the error increased gradually.

\section{Acknowledgement}

We would like to express our thanks to ours students for their valuable discussions and helps to ready for ours experiment. This work has been supported by the key project of Hubei Provincial Department of Education: D20152703.

\section{References}

[1] Agrawal M, Vasyuchka V I, Serga A A, et al. Direct measurement of magnon temperature: New insight into magnon-phonon coupling in magnetic insulators[J]. Physical review letters, 2013, 111(10): 107204.

[2] Yoo J, Estrada-Perez C E, Hassan Y A. An accurate wall temperature measurement using infrared thermometry with enhanced two-phase flow visualization in a convective boiling system[J]. International Journal of Thermal Sciences, 2015, 90: 248-266.

[3] Zhen Y, Shicheng Z, Li Y. Altering spectrum method in temperature measurement using infrared imager[J]. Infrared and Laser Engineering, 2012, 6: 007.

[4] Zhang Q, Ha S T, Liu X, et al. Room-temperature near-infrared high-Q perovskite whispering-gallery planar nanolasers[J]. Nano Lett, 2014, 14(10): 5995-6001.

[5] Hoffmann G, Schmidt M, Ammon C, et al. Monitoring the body temperature of cows and calves using video recordings from an infrared thermography camera[J]. Veterinary research communications, 2013, 37(2): 91-99.

[6] Dolkar R, Kapoor S, Singh N V, et al. A comparative study on the recording of temperature by the clinical mercury thermometer and digital thermometer[J]. Nursing and Midwifery Research, 2013, 9(1): 40-46.

[7] Smith J, Alcock G, Usher K. Temperature measurement in the preterm and term neonate: a review of the literature[J]. Neonatal Network, 2013, 32(1): 16-25.

[8] Shen Z, Zheng S, Dong K, et al. Subperitoneal pelvic exposure of elemental mercury from a broken thermometer[J]. Clinical Toxicology, 2012, 50(2): 145-148.

[9] Childs P R N, Greenwood J R, Long C A. Review of temperature measurement[J]. Review of scientific instruments, 2000, 71(8): 2959-2978.

[10] Snyder W C, Wan Z, Zhang Y, et al. Classification-based emissivity for land surface temperature measurement from space[J]. International Journal of Remote Sensing, 1998, 19(14): 2753-2774. 